\title{
Statistical Thinking in quality improvement: use, difficulties and benefits of its implantation in industries of the Brazilian State of São Paulo
}

\author{
Jose Carlos de Toledo ${ }^{\mathrm{a} *}$, Fabiane Letícia Lizarellia, Adriana Barbosa dos Santos ${ }^{\mathrm{b}}$, Artur lshizaka ${ }^{\mathrm{a}}$ \\ aUniversidade Federal de São Carlos, São Carlos, SP, Brasil \\ bUniversidade Estadual Paulista, São José do Rio Preto, SP, Brasil \\ *toledo@dep.ufscar.br
}

\begin{abstract}
Paper aims: ldentify the use of statistical thinking and techniques and their main difficulties and benefits in the Brazilian State of São Paulo industries.

Originality: There are few empirical studies on the application of the statistical thinking and techniques which study their difficulties of implementation and their benefits in manufacturing companies.

Research method: A web survey of a sample of 243 manufacturing companies.

Main findings: The companies, in general, use some statistical principles and basic techniques for process control and improvement, however, companies that use principles and techniques more consistently have greater operational and team benefits. The main difficulties are associated to lack of culture and knowledge.

Implications for theory and practice: The statistical application enables effective processes improvements and it is associated with motivation for further improvements, consolidation of improvement programs and culture of quality. This finding suggests managerial implications such as to plan actions to deploy and disseminate the culture of statistical thinking in an evolutionary way, training and support for use and to overcome barriers.
\end{abstract}

Keywords

Statistical techniques. Statistical approach. Improvement programs. Perceived benefits.

How to cite this article: Toledo, J. C., Lizarelli, F. L., Santos, A. B., \& lshizaka, A. (2018). Statistical Thinking in quality improvement: use, difficulties and benefits of its implantation in industries of the Brazilian State of São Paulo. Production, 28, e20180062. https://doi.org/10.1590/0103-6513.20180062.

Received: July 16, 2018; Accepted: Nov. 12, 2018.

\section{Introduction}

The use of Statistical Thinking (STk) has been recently highlighted in the quality management literature due to its potential to increase organizations' competitiveness by means of overcoming challenges related to product and process improvement (Hoerl \& Snee, 2010). STk is a reasoning that focuses on the understanding of the unequivocal presence of variation in all activities and on the perception of the production as a series of interconnected processes. Thus, the STk enables the identification, characterization, control and reduction of variability in processes as an opportunity for improvement (Snee, 1990; Hoerl \& Snee, 2012).

Statistical Techniques (STe), already established in the scope of quality management, play a joint role with the STk, encompassing tools and methods that assist the data analysis and processing (Snee, 2004; Pfannkuch \& Wild, 2004; Makrymichalos et al., 2005). 
The STk underlies the application of STe based on the concepts of variability and randomness. Its principles must be well disseminated and applied continuously, allowing potential improvements to be achieved by means of STe (Makrymichalos et al., 2005; Goh, 2011; Coleman, 2013).

The combined use of STk and STe, as part of the methodological framework of improvement programs such as Six Sigma, TQM, Kaizen, Lean, Lean-Sigma, TPM, among others, has contributed to overcome barriers of product and process improvements, increasing organizations' competitiveness. Despite the impetus for the use of STk and STe during the $21^{\text {st }}$ century due to the diffusion of improvement programs, especially Six Sigma, there are still difficulties in their application, maintenance and continuity, both in routine use and in management decision making process (Pfannkuch \& Wild, 2004; Makrymichalos et al., 2005).

Nevertheless, there are still gaps in the literature on the use of STk and STe in Brazilian manufacturing companies. There is also a lack of researches related to the identification of benefits and implementation barriers in manufacturing Brazilian companies. Such benefits have been identified based on the impact on process performance indicators, both objective and subjective. Knowledge of these benefits helps to recognize the importance of applying these principles and methods.

Considering the relevance of the theme, this paper examines the presence and intensity of the use of STk and basic and advanced STe, identifies barriers that hamper their application, and analyses the benefits of using the STk and STe based on process performance indicators. The empirical data of this study came from a survey that included 243 medium and large manufacturing companies in the state of São Paulo, from the following sectors: Food and beverages, Auto parts, Serial capital goods, Consumer goods and personal hygiene, Electronics and home appliances, Pharmaceutical and Chemical industry.

The paper presents the concepts of STk and STe, the research method, the description and analysis of the field research data and the final considerations.

\section{Statistical Thinking and techniques in process improvement}

\subsection{Statistical Thinking}

Statistical Thinking (STk) is defined as a philosophy of learning and action, a way of thinking that recognizes production systems as a series of interconnected processes, which must have their variations identified, quantified and reduced as a way of providing improvement opportunities (Snee, 1990). According to Snee (2004) and Coleman (2013), STk refers to a process of awareness, wherewith processes are analyzed through the use of STe assuming the presence of variation. When disseminated at a strategic level in the organization, the STk generates a greater impact and rationality to the actions making than the use of STe alone. By attempting to improve processes by reducing variability, STk plays a key role, since it encourages the dissemination and use of statistical tools and concepts at the tactical and operational levels of the organization (Snee, 1990; Hoerl \& Snee, 2012).

In order to operationalize the STk, there should be a deployment of principles and practices, such as process data measurement and collection, problem resolution based on facts and data, focus on improving the whole process instead of isolated operations, identification and analysis of potential sources of variation originated from machines, people, materials, methods, measurements and environment (Snee, 1990; Makrymichalos et al., 2005; Hoerl \& Snee, 2012; Hoerl et al., 2014). Process improvement based on STk is related to the reduction and elimination of variability, which contributes to keeping the processes in a statistical control state, that is, only under effect of common causes (Pfannkuch \& Wild, 2004).

STk principles should be disseminated at all levels of the company by means of awareness and training. These principles should be understood by operational employees, supervisors, and senior managers (Snee, 1990; Abraham, 2005). For effective dissemination, top management commitment is required, for the employees to get a true understanding of these principles (Abraham, 2005).

The study of process variability, its quantification and reduction are crucial issues for quality improvement (Snee, 1990; Pfannkuch \& Wild, 2004; Makrymichalos et al., 2005; Hoerl \& Snee, 2012). The quality of data is indispensable for improvement activities and variability reduction. The data may contain errors associated to collection failures or in the measurement system, which directly affect the performance of the application of statistical methods (Wild \& Pfannkuch, 1999; Makrymichalos et al., 2005).

The process vision is part of the core of the STk, and it relies on the procedure of analysis of the data, which should allow a full understanding of the process (Pfannkuch \& Wild, 2004; Makrymichalos et al., 2005; Hoerl et al., 2014). The incorporation of STk in the process analysis emphasizes the importance of data measurement, based on adequate sampling procedures, to guarantee the validity and reliability of the analysis (Hoerl \& Snee, 2009). Table 1 presents the STk principles. 
Table 1. Statistical Thinking principles.

\begin{tabular}{|c|c|}
\hline STk principles & Authors \\
\hline Continuous training and dissemination of STk principles & Snee (1990), Abraham (2005) \\
\hline Top management commitment to the STk principles implementation & Abraham (2005) \\
\hline Interconnected processes vision & Snee (1990), Makrymichalos et al. (2005), Hoerl \& Snee (2012) \\
\hline Understanding of the need to quantify and reduce variability & Snee (1990), Makrymichalos et al. (2005), Hoerl \& Snee (2012) \\
\hline $\begin{array}{l}\text { Importance of the data that is going to be used in the analysis (data } \\
\text { quality) }\end{array}$ & Wild \& Pfannkuch (1999), Makrymichalos et al. (2005) \\
\hline Focus on the data and its measurement & Hoerl \& Snee (2009) \\
\hline Decision making based on facts and data & Hoerl \& Snee (2012) \\
\hline Acknowledge cause-effect relations to analyze variability problems & Makrymichalos et al. (2005) \\
\hline
\end{tabular}

\subsection{Statistical Techniques}

The principles and concepts of STk support the strategy and methods to solve processes' problems using statistical tools and techniques (Snee, 2004; Makrymichalos et al., 2005; Jensen et al., 2012; Goh, 2015). The STk should precede the use of statistical techniques, which are necessary to support and assist the operationalization of the concepts (Britz et al., 2000). STe are designed to uncover patterns in scenarios where phenomena are represented by data, however, to extract reliable information from the data, both collection and analysis must follow statistically-based planning and execution (Grigg \& Walls, 2007). It is the use of STe that allows the analysis of processes and products, contributing to better business results (Snee, 1998; Goh, 2011).

The techniques that allow the identification, characterization and prioritization of problems and possible causes can be divided into basic (Check Sheets, Histograms, Scatter Diagrams, Stratification, Cause-Effect Diagrams, Pareto Diagrams, Sequential Graphs, among others), intermediate (Statistical Process Control, Sampling Techniques, Statistical Inference, Non-Parametric Methods, Process Capability Analysis) and advanced (Taguchi Method, Design of Experiments, Response Surface, Multivariate Analysis, ANOVA, Multiple Regression Analysis, among others) (Xie \& Goh, 1999; Evans \& Lindsay, 2005; Makrymichalos et al., 2005).

The tools and techniques allow identifying, characterizing and prioritizing the problems and their causes (Evans \& Lindsay, 2005), and their use provide opportunities for process improvement as a consequence of data measurement, collection and statistical analysis (Britz et al., 2000; Toledo et al., 2018).

\subsection{Barriers to the implementation of STk and STe}

A study by Ahmed \& Hassan (2003) with Malaysian industrial companies showed that the lack of support and involvement of top management, coupled with the lack of appropriate statistical knowledge, compromised the implementation of STe. Grigg \& Walls (2007) also reported the lack of management support, the lack of statistical knowledge, and the inadequate system of data measurement and collection as barriers to the implementation of STe in companies.

Employee resistance and lack of statistical knowledge are the most critical barriers for the adoption of statistical quality techniques (Laureani \& Antony, 2017; Lim et al., 2017). Table 2 presents the barriers to the application of STk and STe in processes.

Table 2. Barriers to the application of STk and STe.

\begin{tabular}{ll}
\hline \multicolumn{1}{c}{ Barriers categories } & \multicolumn{1}{c}{ Barriers } \\
\hline Managerial view & - Statistics is applied, especially in operational level, being little used in managerial decision making. \\
& - Lack of support and involvement of top management on promoting and applying STk and STe. \\
& - Belief that STe are short-term initiatives, not capable of delivering sustainable improvements. \\
& - In general, managers cannot distinguish common and special causes of variance in key business \\
& - Managers and engineers have difficulty in approach processes focusing on variability. \\
Education and technical qualification & - Lack of appropriate statistical and technical knowledge by managers and engineers. \\
& - Discrepancy between the theoretical knowledge about STe and the organizations' needs. \\
\hline
\end{tabular}

Source: Bjerke \& Hersleth (2001); Makrymichalos et al. (2005); Bisgaard et al. (2008); Abraham (2005); Firka (2011); Ahmed \& Hassan (2003); Grigg \& Walls (2007); Montgomery (2010); Coleman (2013). 
In contrast to the barriers, some authors discuss success factors for the implementation of STk and STe that include: employment of facilitators, statisticians or engineers with adequate statistical knowledge for training and practical guidance to the use of STk and STe to employees at all hierarchical levels, facilitating and guiding managers in decision making; utilization of routine examples to demonstrate application possibilities and achieved results; allocation of professionals with experience in STe in new improvement projects to disseminate and consolidate this specific knowledge (Abraham, 2005; Makrymichalos et al., 2005; Snee, 2005; Hoerl \& Snee, 2010).

\subsection{Benefits of the Statistical Thinking and Statistical Techniques}

International literature considers that the use of STk and STe contributes to improve organizations' results. Deming (1986) points out that the use of STk and STe should emphasize the reduction of process variability, since, as variability is reduced, benefits arise, such as reduction of non-conformities, waste and non-quality costs. Grigg \& Walls (2007) highlight benefits that include reducing non-conformities, waste, non-quality costs and customer complaints, as well as improvements in process efficiency. The reduction of process variability promotes results such as reduction of costs of product defects, increased revenue and customer satisfaction (Snee, 1998; Makrymichalos et al., 2005; Goh, 2011; Hoerl \& Snee, 2012).

The dissemination and effective use of STk principles and STe also provide benefits that are not directly associated with objective performance indicators, but indirectly promote performance improvements, such as better understanding of cause-effect relations, process vision, perception of problems and process variability by business professionals, as well as fostering involvement in improvement programs and projects (Makrymichalos et al., 2005). These can be considered subjective results, assessed by perception, and not by direct indicators.

Although benefits are highlighted in the literature, there are no studies in Brazilian manufacturing companies that justify the association of the use of STk and STe to the expected benefits, neither based on objective performance indicators nor with indirect and more subjective results. Additionally, there are no studies about the difficulties faced by Brazilian companies on the implementation and use of STk and STe, which may hinder the achievement of its benefits. The recognition of these benefits may indicate a willingness of companies to maintain the use of STk and STe, which could encourage other companies to do the same.

In order to guide the selection of variables and their respective questions in the research instrument (questionnaire), the following topics were considered: the deployment of STk principles; basic, intermediate and advanced STe; importance of quality for the company's competitive strategy; formal training for the application of STk and STe; improvement programs adopted and the potential benefits, objective and subjective, that can be achieved with the use of STk and STe.

\section{Research method}

An web survey was planned to empirically support this descriptive research, with the purpose of analysing the intensity of the use of STk and STe and the perceived benefits in medium and large manufacturing companies, of several industrial sectors, located in the state of São Paulo, which has implemented some improvement program. Due to the intended scope and limited resources to make satisfactory results feasible, the web survey was chosen as data collection procedure. This is an advantageous procedure considering its low cost, flexibility in the design of the questionnaire, potential to reach a large number of respondents, possibility to add required questions to the questionnaire, quickness in the application, responses control, ease of storage and tabulation of data, among others (Dillman, 2000; Fricker Junior \& Schonlau, 2002; Evans \& Mathur, 2005; Fan \& Yan, 2010).

Three research questions guided the pursuit of this goal:

\section{Q1:At what degree are manufacturing companies using STk and STe?}

Q2:What are the barriers or difficulties that hinder the application of STk and STe in these companies?

\section{Q3:What benefits are associated by the use of STk and STe?}

In order to discuss the answers to these questions and guide the search for empirical evidence, the following hypotheses were formulated:

$\mathrm{H} 1$ : The application of STk and STe is associated with objective benefits, which reflect the performance of manufacturing processes; 
H2:The application of STk and STe is associated with subjective satisfaction benefits.

The research scope was delimited to medium and large manufacturing companies that belong to seven industrial sectors, located in the state of São Paulo. The state of São Paulo was chosen because it is the geographic region with the highest industrial concentration in Brazil, and besides, it contains the largest industrial park in Latin America with significant representation in the national context in the following sectors: Food and beverages, Auto parts, Serial Capital goods, Consumer goods and personal hygiene, Electronics and home appliances, Pharmaceutical and Chemical industry. These industrial sectors are considered dynamic and competitive, and in principle they should adopt relatively more improvement initiatives and methods than others.

The development of the statements used in the research instrument was based on the concepts identified in a bibliographic review. Guidelines for the better elaboration of questionnaires, found in the literature related to the web survey research method, were followed, giving special attention to aspects that contribute to improve the reliability and validity of the data (Dillman, 2000; Boyer et al., 2002; Creswell, 2009; Zhang et al., 2016). The conduction of the research aimed to minimize the main types of web survey errors, which include sampling (use of biased samples), coverage (lack of access to the target population), measurement errors (inadequate formulation of the questionnaire) and lack of responses (non-respondents) (Dillman, 1991; Couper, 2000).

To identify the population of companies to be sampled, the lists of the members of the cited sectors' syndicates were used. This procedure resulted in a total of 735 industrial plants identified and contacted. In order to minimize coverage errors, which are linked to difficulties in accessing the target population, it was identified the target respondents in each plant. The questionnaires were directed to production managers, quality managers or improvement programs managers, assuming that they were the people with the adequate profile to answer reliably to the questionnaire. These professionals were contacted via email or phone calls and were invited to participate in the survey. The invitation email included an explanation of the research, basic instructions for accessing the electronic questionnaire and a clarification on the guarantee of confidentiality of the information provided. The questionnaire was sent to the 735 industrial plants and the sample was formed by the industrial plants respondents that fill out the full questionnaire.

The questionnaire was developed using the Google Research tool and to minimize measurement errors a pre-test was carried out, on face-to-face interviews in ten companies, which allowed adjustments to improve understanding and focus.

In an effort to increase the response rate, after sending the web survey invitation email, a reminder email was sent two weeks later, for those who did not respond, a third wave of emails was sent approximately one and a half months after the first submission. The method used was saturation surveying, this method attempts to survey all identifiable targets and overcomes the lack of reliable sampling frames (Bradley, 1999; Chipp et al., 2007).

The data collection procedure achieved a sample of 243 respondents, with sub-samples of at least 30 respondents of each of the 7 industrial sectors cited above. The response rate of 33.1\% was considered satisfactory, when compared with other studies carried out in Brazil with similar characteristics (Pinto \& Carvalho, 2008; Santos \& Antonelli, 2011; Oprime et al., 2011; Jabbour et al., 2013). Great care was taken to obtain a satisfactory response rate and was obtained a satisfactory sample considering the Tipe 1 error (.05), statistical power (.06) and small effect proposed by Forza (2002). Bergquist \& Albing (2006) affirm that other surveys measuring the use of statistical techniques have observed response rates in the 15-27\% range. Even considering the size of the sample by sector, the lowest response rate was $27 \%$, which is also a high response rate compared to similar studies.

The questionnaire was composed of 48 questions, arranged in four sections:

A. General information of the company, certified management systems and improvement programs (6 questions);

B. Application of Statistical Thinking principles and concepts (13 questions);

C. Application of Statistical Techniques - basic, intermediate and advanced (14 questions);

D. Objective and subjective perceived benefits of the application of STk and STe (15 questions).

Responses were measured using a five-point likert scale for frequency of use (sections B and C) and for level of agreement (section D). An electronic page was constructed to make the questionnaire accessible via an internet link.

Univariate and multivariate statistical analysis were applied. The former included calculations of frequencies, percentages, basic graphs and non-parametric tests that allowed a general overview of the variables in each question of the questionnaire. The later included a Factor Analysis, which allowed a reliability analysis of the answers of main sections of the questionnaire. Cronbach's alpha coefficient was used to evaluate if the variables 
identified in each section of the questionnaire could be used as indicators of the same construct, being, thus, interrelated (Hair Junior et al., 1998).

Principal component analysis was used to identify underlying factors of the 13 items of section B, related to the application of STk principles and concepts, since, unlike STe, STk variables generally refer to behaviors. Fisher's exact test was performed for comparison of two proportions, and the non-parametric Mann-Whitney test for comparison between groups of companies. A significance level of 5\% was adopted for the statistical tests, using the software MS Excel 2013 and SPSS 16.0.

\section{Results}

\subsection{Sample profile}

Among the 243 respondents, 152 companies (62.6\%) have more than 500 employees and 91 companies (36.4\%) have between 100 and 500 employees. The most frequent certifications are: ISO 9001 (67.5\%); ISO 14001 (43.2\%); GMP/HACCP (21.8\%); TS 16949 (12.8\%); ISO 22000 (7.4\%); OHSAS 18001 (5.8\%); 1SO 17025 (3.7\%). In most cases, respondents attributed a high degree of importance to quality in company's competitive strategy (75.2\% of the sample).

Regarding the use of improvement programs, it can be seen in Table 3 that Kaizen events, day-to-day improvement initiatives, suggestion boxes and $5 \mathrm{~S}$ are the most commonly found programs in the investigated organizational context, being prioritized according to the industrial sector. However, programs that advocate the use of STe and that are relatively more complex, such as Six Sigma, Lean Manufacturing, Lean Sigma, TPM and TQM, are less present.

Table 3. Importance of quality and Improvement Programs.

\begin{tabular}{|c|c|c|c|}
\hline Characteristics & & Results & \\
\hline \multicolumn{4}{|c|}{ Importance of quality for the competitive strategy $(n=243)^{*}$} \\
\hline Low & & $8(2.9 \%)$ & \\
\hline Medium & & $53(21.9 \%)$ & \\
\hline High & & $182(75.2 \%)$ & \\
\hline Improvement Programs & Do not have & $<5$ years & $>5$ years \\
\hline Kaizen $(n=220)$ & $84(38.2 \%)$ & $71(32.3 \%)$ & $65(29.5 \%)$ \\
\hline Day-to-day Improvement Initiatives $(n=233$ ) & $21(9.0 \%)$ & $89(38.2 \%)$ & $123(52.8 \%)$ \\
\hline Suggestion Box $(n=222)$ & $62(27.9 \%)$ & $68(30.6 \%)$ & $92(41.5 \%)$ \\
\hline Six Sigma $(n=219)$ & $104(47.5 \%)$ & $61(27.8 \%)$ & $54(24.7 \%)$ \\
\hline Lean manufacturing $(\mathrm{n}=213)$ & $69(32.4 \%)$ & $76(35.7 \%)$ & $68(31.9 \%)$ \\
\hline Lean sigma $(n=203)$ & $140(69.0 \%)$ & $37(18.2 \%)$ & $26(12.8 \%)$ \\
\hline TPM (n=203) & $92(45.3 \%)$ & $47(23.2 \%)$ & $64(31.5 \%)$ \\
\hline TQM $(n=204)$ & $124(60.8 \%)$ & $32(15.7 \%)$ & $48(23.5 \%)$ \\
\hline $5 S(n=233)$ & $18(7.7 \%)$ & $84(36.1 \%)$ & $131(56.2 \%)$ \\
\hline
\end{tabular}

*The value $n$ corresponds to the number of valid responses. Source: Field research.

Table 4 shows that more than half of the companies (55.8\%) do not carry out systematic actions towards the dissemination, training and application of both STk and STe, and among the 106 companies that do have some set of initiatives, 64 of them implanted these actions less than 5 years ago. 1t indicates that these initiatives for the diffusion and application of STk and STe are recent and scarce. According to Table 4, 198 companies $(83.5 \%)$ reported that there was little or no increase in investments in specific actions towards training and application of STk and STe principles in the last 5 years. The Pharmaceutical sector positively stood out in this respect: $62.2 \%$ of the companies in this sector indicated some increase of the investment. In contrast, $72.7 \%$ of the Consumer goods and personal hygiene sector companies did not make any additional investment in these actions in the last five years.

\subsection{Application of STk principles}

The results presented in Table 5 identify topics related to the application of STk principles. The percentages refer to the high frequency of the use of each item (sum of the alternatives: "Often" or "Always"). 
Table 4. Actions and investments towards the diffusion of STk and STe principles.

\begin{tabular}{lr}
\hline \multicolumn{1}{c}{ Type } & Results \\
\hline Systematic actions towards diffusion and training and application of STk and STe principles $(\mathrm{n}=240)$ & $42(17.5 \%)$ \\
Present for 5 or more years & $64(26.7 \%)$ \\
Present for less than 5 years & $134(55.8 \%)$ \\
Not present & \\
\hline \multicolumn{1}{c}{ Investments in training and application of STk and STe in the last 5 years $(\mathrm{n}=237)$} & $108(45.6 \%)$ \\
\hline No increase & $90(37.9 \%)$ \\
Little increase & $39(16.5 \%)$ \\
Significant increase &
\end{tabular}

Table 5. Application of STk principles.

\begin{tabular}{lc}
\hline \multicolumn{1}{c}{ Topics related to STk principles in the organization } & High Frequency" \\
\hline 1. Continuous training about STk principles & $10.7 \%$ \\
2. Top management support for the application of STk principles & $32.9 \%$ \\
3. The application of STk principles is disseminated and fostered & $13.7 \%$ \\
4. The main process is under statistical control & $27.6 \%$ \\
5. Process vision is consolidated among supervisors and managers & $50.2 \%$ \\
6. Process vision is consolidated for operators & $18.9 \%$ \\
7. lt is understood that variability is present in all processes & $38.2 \%$ \\
8. lt is understood that there is a need to quantify variability & $37.4 \%$ \\
9. Data collection is questioned by managers and supervisors & $32.6 \%$ \\
10. The application of measurement system analysis & $21.8 \%$ \\
11. Decision making based on facts and data & $40.7 \%$ \\
12. Perform analyses considering cause-effect relations & $55.6 \%$ \\
13. Awareness about the critical role of variability reduction for the manufacturing performance & $60.5 \%$ \\
\hline *High Frequency refers to the proportion of "Often" and "Always" in the answers. Frequency: 1 = Never; $2=$ Rarely; $3=$ Sometimes; $4=0$ Often;
\end{tabular}

5 = Always. Source: Field Research.

Table 5 show that, in general, there is appreciation and concern about the use of STk. It is noticed that the understanding of how critical the variability reduction is for manufacturing performance (item 13) has been achieved, with high frequency in 60.5\% of the companies; the consideration of cause-effect relations in the analysis of products and processes data (item 12) in 55.6\%; and consolidation of process vision at the supervisory and management level (item 5) in 50.2\% of the companies. On the other hand, continuous training on STk principles (item 1) occurs with high frequency in only 10.7\% of the companies; the dissemination of the application of STk principles (item 3) in only 13.7\%; and the process vision has been consolidated at the level of operators (item 6) in a high frequency in only $18.9 \%$ of the companies.

The results obtained for items 2, 4, 7, 8 and 11, and especially the results of the items 1, 3 and 6, indicate that there is no high frequency in the application of practices and behaviors for the implementation of STk principles. They are evidences of obstacles to the dissemination and application of STk principles in the companies of the sample, as indicated by Montgomery (2010). Despite the concern about facts and data-based decision making and an understanding of the critical role of variability reduction, there is little questioning about the data obtained (item 9), that showed a high frequency in only $32.6 \%$ of the companies, which coincides with the observations of the field research of Ahmed \& Hassan (2003). It is noticed that these concepts of the STk are not being practiced and valued jointly and simultaneously, however they are all being diffused, albeit at different degrees of priority.

In order to identify factors that reveal the interrelation between items that are possibly being valued by the companies, regarding the use of STk principles, a Principal Components Analysis was performed on these 13 items. This analysis aimed to identify a set of underlying factors that explains a substantial portion of the information from the set of 13 variables. The study of the principal components made it possible to identify three underlying factors that represent the latent structure of the data referring to topic B of the questionnaire:

- Factor 1: Focus on data and quantification of process variability, resulting from the interrelation between items 8 to 13 ; 
- $\quad$ Factor 2: Managerial support for diffusion of STk principles, resulting from the interrelation between items 1, 2 and 3;

- $\quad$ Factor 3: Process vision, derived from the interrelation between items 5, 6 and 7.

According to the Factor Analysis, 71.9\% of the total variance was explained by these 3 factors, where Factor 1 alone accounted for $54.1 \%$ of the total variance. This factor, identified as "Focus on data and quantification of process variability", is a result of the interrelation of items 8 to 13 and indicates an interrelated set of STk principles more closely related to the application of STe. The items 8, 9, 10 and 13 are also associated with the quantification and analysis of the variability that would be applied in a more articulated way. On the other hand, the results indicate that Factor 2, identified as "Managerial support for diffusion of STk principles", would be less prioritized in the whole.

A Cronbach's alpha coefficient of 0.927 revealed that the variables associated with each of the 13 items measure the same construct satisfactorily (Hair Junior et al., 1998).

\subsection{Application of Statistical Techniques}

From the survey on the intensity of use of basic, intermediate and advanced statistical techniques (Figures 1 and 2), it is observed that only a few basic and intermediate techniques are being used more intensely, such as the Pareto Diagrams, Cause-Effect Diagrams, Check Sheets and Sampling Plans. These techniques are used in more than $50 \%$ of the companies of the sample. Scatter Diagrams and Linear Regressions, two well-connected tools, are only used sporadically (never or rarely). More complex tools are also used in greater proportion only sporadically, since for all advanced STe there were more than 63\% of the responses concentrated in sporadic use. Multiple Regression and Multivariate Analysis techniques are never used by $63.4 \%$ and $65 \%$ of firms, respectively.

The consistency of the answers was adequate for the items of topic $\mathrm{C}$ of the questionnaire, according to the Cronbach's alpha of 0.898 .

Sampling plans

$\mathrm{CPk}$

Control Charts

Linear Regression

Check Sheets

Stratification

Cause-Effect Diagram

Scatter Diagram

Pareto Diagram

Histogram

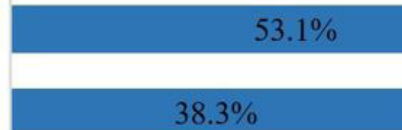

$38.3 \%$

$41.6 \%$ $20.6 \%$

$11.1 \% \quad 20.6 \%$
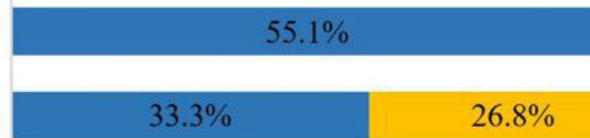

$26.8 \%$
$24.3 \%$

$68.3 \%$

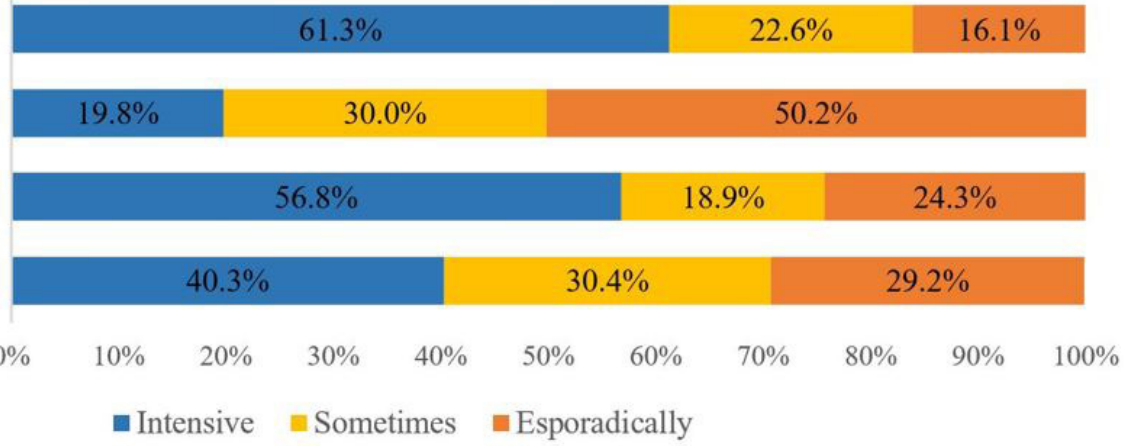

Figure 1. Distribution (\%) of the use of basic or intermediate STe by intensity. 


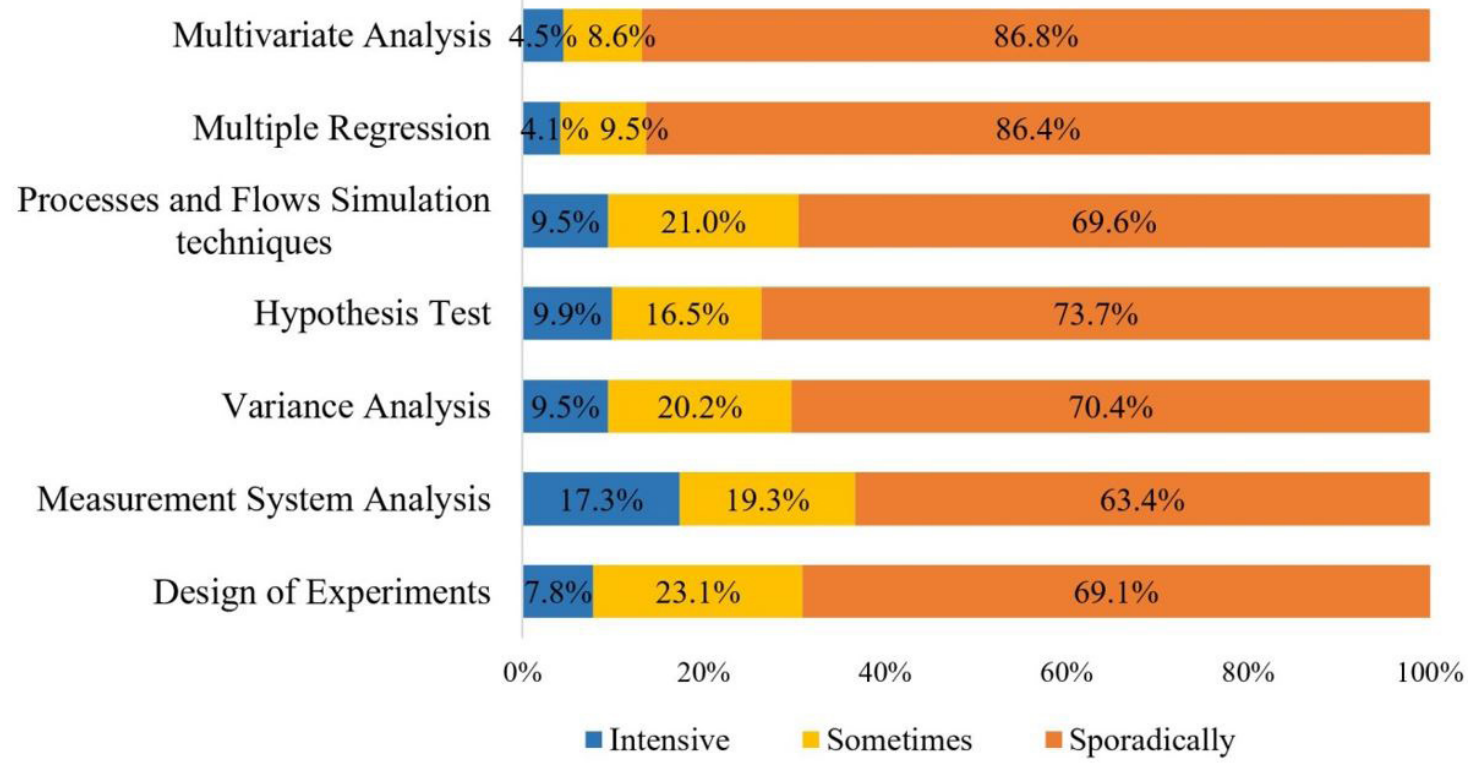

Figure 2. Distribution (\%) of the use of advanced STe by intensity.

\subsection{Barriers to the application of Statistical Thinking and Techniques}

Among the 243 companies in the sample, 115 (47.3\%) answered that they do not systematically apply the principles of STk and STe for process control and quality improvement (Table 6). The sample was split into two groups. The Food and beverages, Auto parts, Consumer goods and personal hygiene, Electronics and home appliances sectors are constituted by a greater proportion of companies that make systematic use of STk and STe in comparison to those that do not use them.

Table 6. Systematic application of STk and STe by group of sectors.

\begin{tabular}{cccc}
\hline \multirow{2}{*}{ Sector groups } & \multicolumn{2}{c}{ Systematic application of STk and STe* } & \multirow{2}{*}{$\begin{array}{c}\text { P value } \\
\text { (Fisher's exact test) }\end{array}$} \\
\cline { 2 - 3 } & Group NA & Group A & 0.020 \\
G1 & $53(40.1 \%)$ & $79(59.9 \%)$ & \\
Total & $62(55.8 \%)$ & $128(54.1 \%)$ & \\
\hline
\end{tabular}

*Group NA = does not systematically apply STk and STe; Group A = systematically applies STk and STe. Source: Field research.

This group of sectors was called G1. In this group, 59.9\% of the companies systematically apply STk and STe. The G2 group is constituted of companies in the Pharmaceutical, Serial capital goods and Chemical industry, in which the proportion of companies that systematically use STk and STe is lower than those that do not. $\ln$ G2, $44.1 \%$ of companies apply STk and STe. This difference is statistically significant, at the significance level of 5\%, by Fisher's exact test $(\mathrm{P}$ value $=0.020)$, which shows that there may be distinction regarding the importance of statistics in management and quality improvement areas, depending on the industrial sectors that are part of the group. It also suggests possible differences in managerial vision regarding the potential and application of STk and STe in production routine, depending on the sector.

Among the reasons of companies that do not systematically apply STk and STe, 66.0\% of the 115 companies argue that "apply sporadically, due to external demands and other company priorities". For 57\% of the companies, the barrier is "lack of a suitable culture for the application of STk / STe", and for 57\% there is "lack of internal knowledge that supports the systematic application". On the other hand, "we do not feel the need for systematic / routine application" and "we do not believe in the potential of the application" was the response of only 13\% of the companies (Table 7). The least mentioned barriers are the ones related to discredit in it's 
Table 7. Percentage of agreement with the motives for not systematically apply STk and STe.

\begin{tabular}{lc}
\hline \multicolumn{1}{c}{ Motives } & Percentage of agreement \\
\hline Lack of a suitable culture for the application of STk/STe & $66 \%$ \\
Applies sporadically, due to external demands and other company priorities & $57 \%$ \\
Lack of internal knowledge that supports the systematic application & $57 \%$ \\
The level of training and knowledge does not allow the application & $28 \%$ \\
There is a predominant view that the application of STk/STe is complex & $26 \%$ \\
There isn't a belief on the potential of the application of STk/STe & $13 \%$ \\
We do not feel the need for a systematic application & $13 \%$ \\
Managers see STk/STe as a "firefight" tool only & $10 \%$ \\
Managers believe that STk and STe can only be applied in operational level, and they are not & $3 \%$ \\
important for managerial and strategical issues & $3 \%$
\end{tabular}

Source: Field research.

potential, no perception of its necessity, "firefighting" application only and operational level usage only, which shows that lack of application is more related to the lack of culture and of knowledge for it than in a possible belief that STk and STe are not effective.

\subsection{Perceived results}

The performance of manufacturing processes in the previous 3 years, perceived as influenced by the use of STk and STe, was evaluated both by objective indicators, such as nonconformity indices, and by subjective indicators of perceived satisfaction with STk and STe, such as greater commitment to the control and improvement of the process by professionals who participate in the improvement actions at a tactical and operational level.

Companies that systematically apply STk and STe (Group A) were compared to those that did not systematically apply them (Group NA). This division was based on the companies' perception on the application of STk and STe, presented in Table 6 . The comparison was based on the proportion of positive responses reported in each item, evaluated for both sets of indicators. Responses 4 or 5 , on the Likert scale from 1 to 5 , were considered positive. Fisher's exact test (Table 8 ) provided evidence of a statistically significant difference between groups A and NA at a significance level of 5\% for the following objective indicators: "reduction of the internally identified nonconformities index" ( $\mathrm{P}=0.0063)$; "Reduction of customer index complaints/returns" $(\mathrm{P}=0.0346)$; and "increased customer satisfaction" ( $\mathrm{P}=0.0489)$. In these indicators the highest proportion occurred in group $A$, which applied STk and STe in a greater intensity. For the other objective indicators there was no statistically significant difference between the two groups $(\mathrm{P}>0.05)$.

For the indicators of perceived satisfaction with the application of STk and STe, the statistically significant difference between groups A and NA was evident for: "manager's level of satisfaction on the application of STk and STe" $(P=0.0022)$; and "change of organizational culture in favor of quality" $(P=0.0216)$. For the other indicators of this category there was no statistically significant difference $(P>0.05)$. Although the comparison for the indicator "Contribution of the application of STk and STe for consolidation of improvement programs" presented a P value of 0.1044 , it indicates potential perception of impact of STk and STe on improvement programs.

The consistency of responses for topic D of this questionnaire, on perceived performance, was good, as measured by Cronbach's alpha of 0.9579 .

Group NA should be viewed as a low STk and STe application group, and it can be noticed on Table 8 that for most of the indicators there are no significant differences between the companies that make the most use and the ones with the lowest use of STk and STe. This indicates the possibility that intervenient or contextual factors may have influenced perceived results, or that there are specific companies in which the routine use of STk and STe is not necessary. The differences are associated with specific indicators, such as the reduction of internal and external non-conformities, therefore related to the quality improvement of process, which are more directly associated with STk and STe and to the improvement programs in manufacturing processes. Other indicators, such as reduction of cycle time, may be more associated with other improvement actions and initiatives, such as process flow analysis.

A joint analysis of the benefits perceived by the companies of groups A and NA was carried out, considering the following indicators of global benefits: 
Table 8. Percentage of companies with positive responses to objective indicators and perceived satisfaction with the application of STk and STe.

\begin{tabular}{|c|c|c|c|}
\hline \multirow[b]{2}{*}{ Indicator } & \multicolumn{2}{|c|}{ Positive responses* } & \multirow[b]{2}{*}{ P Value ${ }^{* *}$} \\
\hline & $\begin{array}{l}\text { Group A } \\
(n=128)\end{array}$ & $\begin{array}{c}\text { Group NA } \\
(n=115)\end{array}$ & \\
\hline \multicolumn{4}{|l|}{ Objective (Process Performance) } \\
\hline 1. Reduction of the index of internally identified non-conformities & $41.4 \%$ & $24.4 \%$ & 0.0063 \\
\hline 2. Reduction of customer index complaints/returns & $43.8 \%$ & $30.4 \%$ & 0.0346 \\
\hline 3. Increased level of customer satisfaction & $46.1 \%$ & $33.0 \%$ & 0.0489 \\
\hline 4. Reduction in non-quality costs & $39.8 \%$ & $33.9 \%$ & 0.3546 \\
\hline 5. Reduction of production cycle (time) & $32.8 \%$ & $33.9 \%$ & 0.8920 \\
\hline 6. Reduced production costs & $29.7 \%$ & $26.1 \%$ & 0.5689 \\
\hline 7. Increased productivity & $38.3 \%$ & $40.0 \%$ & 0.7938 \\
\hline 8. Improvement of process capability indices (CPk) & $35.9 \%$ & $30.4 \%$ & 0.4141 \\
\hline \multicolumn{4}{|l|}{ Perceived satisfaction with the application of STk and STe } \\
\hline 1. Manager satisfaction level & $39.1 \%$ & $20.9 \%$ & 0.0022 \\
\hline 2. Operational level employee motivation in the application of STk and STe & $18.8 \%$ & $13.9 \%$ & 0.3868 \\
\hline 3. Increased understanding of the process and problem-solving ability & $29.7 \%$ & $22.6 \%$ & 0.2441 \\
\hline 4. Contribution of the use of STk and STe to consolidate improvement programs & $39.1 \%$ & $28.7 \%$ & 0.1044 \\
\hline 5. Variability reduction, process stability and capacity improvement & $33.6 \%$ & $25.2 \%$ & 0.1623 \\
\hline $\begin{array}{l}\text { 6. Increased concern about measuring and understanding the variability of } \\
\text { processes and their causes }\end{array}$ & $46.1 \%$ & $37.4 \%$ & 0.1937 \\
\hline 7. Change in organizational culture in favor of quality & $41.4 \%$ & $27.0 \%$ & 0.0216 \\
\hline
\end{tabular}

*Group NA = does not systematically apply STk and Ste; Group A = Systematically applies STk and STe; **Fisher's exact test P Value for difference between Groups A and NA. Source: Field research.

$$
\mathrm{BI}_{\mathrm{obj}}=\frac{\text { Number of positive responses for objective indicators }}{8}
$$

and

$$
\mathrm{BI}_{\mathrm{ps}}=\frac{\text { Number of positive responses for perceived satisfation }}{7}
$$

When comparing groups A and NA, using a Mann-Whitney test, it was noticed that there was no significant difference for $\mathrm{BI}_{\mathrm{obj}}(\mathrm{P}=0.0723)$, suggesting that the systematic application of STk and STe is not being perceived as influencing the performance of the main processes. This result shows that there is no confirmation of the general research hypothesis H1 ("The application of STk and STe is associated with objective indicators improvements") for the significance level of 5\%. However, for $\mathrm{BI}_{\mathrm{ps}}$ the sample provided evidence of significant difference between groups $(\mathrm{P}=0.0103)$, indicating that the $\mathrm{H} 2$ hypothesis proceeds, thus the more intense application of STk and STe contributes to the increase of satisfaction with subjective indicators. Therefore, in this sample there is a greater perception of more subjective benefits on the more intense use of STk and STe, which points out the need to better understand these findings in future researches, in greater depth, and its implications on management, focus and improvement programs training.

\section{Final considerations}

The analysis identified that companies still have difficulties in training and application of the principles of STk, as well as the consolidation of the process vision by operators. This result found in Brazilian industries is aligned with previous one, such as Makrymichalos et al. (2005), Grigg \& Walls (2007) and Fotopoulos \& Psomas (2009). The process vision is more consolidated at the supervisors and managers level. Other concepts can be considered more widespread, such as the criticality of the reduction of variability and consideration of cause-effect relations in problem analysis.

Using a Principal Components Analysis, that encompassed the principles of STk, the focus on data and quantification of process variability was highlighted by the interrelationship of a set of STk concepts that is more closely related to the application of STe, and that support the quantification and analysis of variability. 
The managerial support for diffusion of the STk principles appears less intensely in a joint analysis, as well as the process vision.

Regarding STe, it is noticed that there is widespread and more intense use of basic tools, such as Pareto Diagram, Cause-Effect Diagram and Sampling Techniques, but there are still difficulties for the application of more advanced tools. This indicates that the actions of improvement programs, in manufacturing processes, are still more focused on solving routine and less complex problems, with less focus on problems and tools of greater complexity. This result is aligned with previous research, which has reported by Antony et al. (1998), Bergquist \& Albing (2006) and Fotopoulos \& Psomas (2009), showing that there is a general and consistent difficulty in using more complex tools.

In this regard, future researches should seek to identify whether more complex problems are being addressed in other areas and projects of the company. Since authors such as Easton \& Rosenzweig (2012) claim that the odds of success are about four and a half times greater for improvement complex projects that use advanced statistical techniques.

With respect to difficulties for the application of STk and STe, the lack of suitable culture and knowledge are still perceived as barriers to be overcome. Companies did not consider that the lack of preventive vision and the lack of vision of the potential of the application in the operational and managerial level are reasons for its non-application. It can be assumed that the importance of the application is already diffused in the companies, however, lacking in effective and routine use, in agreement with Ahmed \& Hassan (2003) and Bergquist \& Albing (2006) results.

This finding suggests managerial implications such as the need to plan actions to disseminate the culture of STk and STe in an evolutionary way, as well as theoretical and practical training and support for continuous use.

The lack of adequate training and knowledge about STk and STe also hamper the application of more advanced techniques to solve more complex problems. This limited use might be hindering better results in operational performance. Makrymichalos et al. (2005), Bergquist \& Albing (2006) and Fotopoulos \& Psomas (2009) point out that the implementation problems of advanced STe is associated with lack of competence and training, agreeing with the barriers and difficulties encountered in this research.

Respecting the benefits perceived by companies that make systematic use of STk and STe, there were differences between objective indicators related to the reduction of internal and external non-conformities and increase in the level of customer satisfaction. This is an indication that the application of STk and STe enables effective improvements of processes and products, which, consequently, positively affect customer satisfaction. It was also possible to verify that the greater use of STk and STe is associated with a perception of better subjective results, related to the motivation of employees for improvement actions, consolidation of improvement programs and quality culture. The companies realize that by encouraging the greater use of such techniques within the working environment, greater process vision and understanding will decrease poor quality or customers' dissatisfaction agreeing with Bamford \& Greatbanks (2005).

Improvement programs highlight that a first step for improvement is to identify and analyze problems, tasks for which the use of STk and STe is adequate. This may not be properly understood by companies, given that there are still difficulties in the use and training in statistics. There is a need to advance research and practical contributions to operationalize statistical principles. Although abstract they found the attitudes of improvement and problem resolution, based on data and measurements in the process analysis. A more intense and effective use of STk and STe is expected to contribute to more sustainable solutions for manufacturing problems.

\section{References}

Abraham, B. (2005). Statistics in business and industry: implementation. International Statistical Review, 73(2), 173-176. http://dx.doi. org/10.1111/j.1751-5823.2005.tb00263.x.

Ahmed, S., \& Hassan, M. (2003). Survey and case investigations on application of quality management tools and techniques in SMls. International Journal of Quality \& Reliability Management, 20(7), 795-826. http://dx.doi.org/10.1108/02656710310491221.

Antony, J., Kaye, M., \& Frangou, J. A. (1998). A strategic methodology to the use of advanced statistical quality improvement techniques. The TQM Magazine, 10(3), 169-176. http://dx.doi.org/10.1108/09544789810214765.

Bamford, D. R., \& Greatbanks, R. W. (2005). The use of quality management tools and techniques: a study of application in everyday situations. International Journal of Quality \& Reliability Management, 22(4), 376-392. http://dx.doi.org/10.1108/02656710510591219.

Bergquist, B., \& Albing, M. (2006). Statistical methods-does anyone really use them? Total Quality Management \& Business Excellence, 178), 961-972. http://dx.doi.org/10.1080/14783360600747762.

Bisgaard, S., Doganaksoy, N., Fisher, N., Gunter, B., Hahn, G., Keller-McNulty, S., Kettenring, J., Meeker, W. Q., Montgomery, D. C., \& Wu, C. F. J. (2008). The future of industrial statistics: a panel discussion. Technometrics, 50(2), 103-127. http://dx.doi. org/10.1198/004017008000000136. 
Bjerke, F., \& Hersleth, M. (2001). Introducing statistical thinking to the food industry: facilitating and inhibiting factors. The Quality Management Journal, 8(3), 49-60. http://dx.doi.org/10.1080/10686967.2001.11918966.

Boyer, K. K., Olson, J. R., Calantone, R. J., \& Jackson, E. C. (2002). Print versus electronic surveys: a comparison of two data collection methodologies. Journal of Operations Management, 20(4), 357-373. http://dx.doi.org/10.1016/S0272-6963(02)00004-9.

Bradley, N. (1999). Sampling for Internet surveys: an examination of respondent selection for Internet research. Market Research Society Journal, 41(4), 1-10. http://dx.doi.org/10.1177/147078539904100405.

Britz, G. C., Emerling, D. W., Hare, L. B., Hoerl, R. W., Janis, S. J., \& Shade, J. E. (2000). Improving performance through statistical thinking. Milwaukee: ASQ Quality Press.

Chipp, K., Goldman, M., \& Kleyn, N. (2007). What they really think: resolving methodological issues in supply chain ethics research. Professional Accountant, 7(1), 112-122.

Coleman, S. Y. (2013). Statistical Thinking in the quality movement \pm 25 years. The TQM Journal, 25(6), 597-605. http://dx.doi. org/10.1108/TQM-06-2013-0075.

Couper, M. P. (2000). Web surveys: a review of issues and approaches. Public Opinion Quarterly, 64(4), 464-494. http://dx.doi. org/10.1086/318641. PMid:11171027.

Creswell, J. (2009). Research design: qualitative, quantitative, and mixed methods approaches. New York: SAGE Publications.

Deming, W. E. (1986). Out of the crisis. Cambridge: Centre for Advanced Engineering Study, Massachusetts Institute of Technology .

Dillman, D. A. (1991). The design and administration of mail surveys. Annual Review of Sociology, 171), 225-249. http://dx.doi. org/10.1146/annurev.so.17.080191.001301.

Dillman, D. A. (2000). Mail and internet surveys: the Tailored Design method. New York: John Wiley \& Sons.

Easton, G. S., \& Rosenzweig, E. D. (2012). The role of experience in six sigma project success: An empirical analysis of improvement projects. Journal of Operations Management, 30(7-8), 481-493. http://dx.doi.org/10.1016/j.jom.2012.08.002.

Evans, J. R. \& Lindsay, W. M (2005). The management and control of quality. Mason: Thomson South-Western.

Evans, J. R., \& Mathur, A. (2005). The value of online surveys. Internet Research, 15(2), 195-219. http://dx.doi.org/10.1108/10662240510590360.

Fan, W., \& Yan, Z. (2010). Factors affecting response rates of the web survey: a systematic review. Computers in Human Behavior, 26(2), 132-139. http://dx.doi.org/10.1016/j.chb.2009.10.015.

Firka, D. (2011). Statistical, technical and sociological dimensions of design of experiments. The TQM Journal, 23(4), 435-445. http:// dx.doi.org/10.1108/17542731111139509.

Forza, C. (2002). Survey research in operations management: a process-based perspective. International Journal of Operations \& Production Management, 22(2), 152-194. http://dx.doi.org/10.1108/01443570210414310.

Fotopoulos, C., \& Psomas, E. (2009). The use of quality management tools and techniques in ISO 9001: 2000 certified companies: the Greek case. International Journal of Productivity and Performance Management, 58(6), 564-580. http://dx.doi.org/10.1108/17410400910977091.

Fricker Junior, R. D., \& Schonlau, M. (2002). Advantages and disadvantages of internet research surveys: evidence from the literature. Field Methods, 14(4), 347-367. http://dx.doi.org/10.1177/152582202237725.

Goh, T. N. (2011). Six sigma in industry: some observations after twenty-five years. Quality and Reliability Engineering International, 27(2), 221-227. http://dx.doi.org/10.1002/qre.1093.

Goh, T. N. (2015). Emerging megatrends in quality engineering and the "New 5S" response. Quality Engineering, 27(4), 450-460. http:// dx.doi.org/10.1080/08982112.2015.1036294.

Grigg, N., \& Walls, L. (2007). Developing statistical thinking for performance improvement in the food industry. International Journal of Quality \& Reliability Management, 24(4), 347-369. http://dx.doi.org/10.1108/02656710710740536.

Hair Junior, J. F., Black, W. C., Babin, B. J., \& Anderson, R. E. (1998). Multivariate data analysis. New York: Prentice-Hall.

Hoerl, R. W., \& Snee, R. D. (2009). Post financial meltdown: what do the services industries need from us now? Applied Stochastic Models in Business and lndustry, 25(5), 509-521. http://dx.doi.org/10.1002/asmb.805.

Hoerl, R. W., \& Snee, R. D. (2010). Statistical thinking and methods in quality improvement: a look to the future. Quality Engineering, 22(3), 119-129. http://dx.doi.org/10.1080/08982112.2010.481485.

Hoerl, R. W., \& Snee, R. D. (2012). Statistical Thinking: improving business performance. New Jersey: John Wiley \& Sons. http://dx.doi. org/10.1002/9781119202721.

Hoerl, R. W., Snee, R. D., \& De Veaux, R. D. (2014). Applying statistical thinking to 'Big Data' problems. Wiley Interdisciplinary Reviews: Computational Statistics, 6(4), 222-232. http://dx.doi.org/10.1002/wics.1306.

Jabbour, A. B. L. S., Alves Filho, A. G., Viana, A. B. C., \& Jabbour, C. J. C. (2013). Práticas de gestão da cadeia de suprimentos e seus eventuais relacionamentos com as prioridades competitivas da produção: evidências empíricas do setor eletroeletrônico à luz de modelagem de equações estruturais. Production Journal, 23(2), 241-256. http://dx.doi.org/10.1590/S0103-65132012005000069.

Jensen, W., Anderson-Cook, C., Costello, J. A., Doganaksoy, N., Hoerl, R. W., Janis, S., O’Neill, J., Rodebaugh, B., \& Snee, R. D. (2012). Statistics to facilitate innovation*: a panel discussion. Quality Engineering, 24(1), 2-19. http://dx.doi.org/10.1080/08982112.201 2.621865 .

Laureani, A., \& Antony, J. (2017). Leadership characteristics for Lean Six Sigma. Total Quality Management \& Business Excellence, 28(3-4), 405-426. http://dx.doi.org/10.1080/14783363.2015.1090291.

Lim, S. A. H., Antony, J., Arshed, N., \& Albliwi, S. (2017). Systematic review of statistical process control implementation in the food manufacturing industry. Total Quality Management \& Business Excellence, 28(1-2), 176-189. http://dx.doi.org/10.1080/147833 63.2015.1050181.

Makrymichalos, M., Antony, J., Antony, F., \& Kumar, M. (2005). Statistical thinking and its role for industrial engineers and managers in the $21^{\text {st }}$ century. Managerial Auditing Journal, 20(4), 354-363. http://dx.doi.org/10.1108/02686900510592043.

Montgomery, D. C. (2010). A modern framework for achieving enterprise excellence. International Journal of Lean Six Sigma, 1(1), 56-65. http://dx.doi.org/10.1108/20401461011033167. 
Oprime, P. C., Mendes, G. H. S., \& Pimenta, M. L. (2011). Fatores críticos para a melhoria contínua em indústrias brasileiras. Production Journal, 21(1), 1-13. http://dx.doi.org/10.1590/S0103-65132011005000008. PMid:22165445.

Pfannkuch, M., \& Wild, C. (2004). Towards an understanding of statistical thinking. In D. Ben-Zvi \& J. B. Garfield (Eds.), The challenge of developing statistical literacy, reasoning and thinking (pp. 17-46). Dordrecht: Kluwer Academic Publishers. http://dx.doi. org/10.1007/1-4020-2278-6_2.

Pinto, S. H. B., \& Carvalho, M. M. (2008). Main quality programs characteristics in large size Brazilian companies. International Journal of Quality \& Reliability Management, 25(3), 276-291. http://dx.doi.org/10.1108/02656710810854287.

Santos, A. B., \& Antonelli, S. C. (2011). Aplicação da abordagem estatística no contexto da gestão da qualidade: um survey com indústrias de alimentos de São Paulo. Gestão \& Produção, 18(3), 509-524. http://dx.doi.org/10.1590/S0104-530X2011000300006.

Snee, R. D. (1990). Statistical thinking and its contribution to total quality. The American Statistician, 44(2), 116-121. http://dx.doi. $\operatorname{org} / 10.2307 / 2684144$.

Snee, R. D. (1998). Getting better business results: using statistical thinking and methods to shape the bottom line. Quality Progress, 31, 102-106.

Snee, R. D. (2004). Six-Sigma: the evolution of 100 years of business improvement methodology. International Journal of Six Sigma and Competitive Advantage, 1(1), 4-20. http://dx.doi.org/10.1504/1JSSCA.2004.005274.

Snee, R. D. (2005). Leading business improvement: A new role for statisticians and quality professionals. Quality and Reliability Engineering International, 21(3), 235-242. http://dx.doi.org/10.1002/qre.634.

Toledo, J. C., Lizarelli, F. L., Aires-Borrás, M. A., \& Martins, M. F. (2018). 0 uso da estatística em grandes e médias empresas de autopeças no estado de São Paulo, Brasil. Innovar, 28(70), 81-98. http://dx.doi.org/10.15446/innovar.v28n70.74450.

Wild, C. J., \& Pfannkuch, M. (1999). Statistical thinking in empirical enquiry. International Statistical Review, 67(3), 223-248. http:// dx.doi.org/10.1111/j.1751-5823.1999.tb00442.x.

Xie, M., \& Goh, T. N. (1999). Statistical techniques for quality. The TQM Magazine, 11(4), 238-242. http://dx.doi.org/10.1108/09544789910272913.

Zhang, A., Luo, W., Shi, Y., Chia, S. T., \& Sim, Z. H. X. (2016). Lean and Six Sigma in logistics: a pilot survey study in Singapore. International Journal of Operations \& Production Management, 36(11), 1625-1643. http://dx.doi.org/10.1108/lJOPM-02-2015-0093. 